\title{
A fraternidade em questão: um olhar psicossociológico sobre o cuidado e a "humanização" das práticas de saúde
}

SÁ, M.C. On fraternity: a psychosociological view of healthcare and the humanization of healthcare practices. Interface - Comunic., Saude, Educ., v.13, supl.1, p.651-64, 2009.

This paper aims to discuss some challenges for healthcare production, considering the intersubjective and unconscious processes that condition it. The methodological approach for the analysis is based on theoretical categories from the French school of Psychosociology, from psychoanalytical theory on intersubjective/ group processes and from Work Psychodynamics. The sociability patterns and the dominant means of subjectivation within society impose serious limits on healthcare work. These are additional to the limits of a material, technological or organization nature that are more easily recognized. The intersubjective and unconscious dimension of healthcare work produces effects on the quality of care. The specificity of healthcare work and its demands for psychological work are discussed, examining its consequences for the quality of care. Some possibilities for analyzing and dealing with the intersubjective and unconscious dimension of healthcare work are presented, and these may contribute towards a new way of producing healthcare management.

Keywords: Delivery of healthcare. Subjectivity and management. Humanization of assistance.
O presente artigo se propõe a discutir alguns desafios para a produção do cuidado em saúde, considerando os processos intersubjetivos e inconscientes que o condicionam. A abordagem metodológica de análise se apóia em categorias teóricas da Psicossociologia francesa, da teoria psicanalítica sobre os processos intersubjetivos/grupais e da Psicodinâmica do Trabalho. Os padrões de sociabilidade e os modos de subjetivação dominantes na sociedade impõem sérias limitações ao trabalho em saúde, que se somam às de ordem material, tecnológica ou organizacional, mais facilmente reconhecidas. A dimensão intersubjetiva/inconsciente do trabalho em saúde produz efeitos sobre a qualidade da assistência. A especificidade do trabalho em saúde e suas exigências de trabalho psíquico são discutidas, examinando-se suas consequências para a qualidade do cuidado. Algumas possibilidades de análise e abordagem da dimensão intersubjetiva/inconsciente do trabalho em saúde são apresentadas e podem contribuir para um novo modo de produzir a gestão do cuidado em saúde.

Palavras-chave: Assistência à saúde. Subjetividade e gestão. Humanização da assistência.

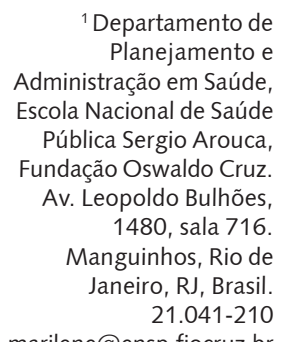




\section{Introdução}

O presente artigo, fruto de uma pesquisa teórica, se propõe a discutir alguns desafios para a produção do cuidado nos serviços de saúde, considerando a característica intersubjetiva do trabalho em saúde e os processos inconscientes que o condicionam. Nos últimos anos, temas como a qualidade e a integralidade da assistência, o trabalho em equipe, o acolhimento e a "humanização" das práticas de saúde vêm ocupando uma posição cada vez mais central na agenda de discussões e na formulação de políticas setoriais, gradativamente chamando a atenção para a importância da dimensão intersubjetiva dos serviços de saúde e de seus processos de trabalho.

Essa temática ganha expressão num contexto em que, a despeito da significativa ampliação de cobertura conseguida pelo SUS, se mantêm iniquidades históricas no acesso ao sistema e se intensificam, nos serviços de saúde, os processos de desvalorização da vida e de banalização do sofrimento alheio presentes na sociedade.

Este quadro põe em questão a efetividade de propostas prescritivo-normativas, que não problematizam o contexto social e político-institucional em que se inserem, e compreendem a "humanização" ou a mudança das práticas de saúde como resultados de um movimento exclusivamente consciente e voluntário dos sujeitos. Cristophe Dejours observou, certa vez, que é impossível prescrever a cooperação. "Ordenar a cooperação (e, poderíamos dizer, a "humanização") é como ordenar o amor, numa ordem do tipo: 'amai-vos uns aos outros', 'cooperai uns com os outros'." (Dejours, 1999, p.29).

Os obstáculos à solidariedade e à produção do cuidado em saúde não residem apenas na precariedade das condições materiais, tecnológicas e na insuficiência de pessoal da grande maioria dos serviços, nem somente nas características dos modelos assistencial biomédico e gerencial funcionalista dominantes. Somando-se a esses fatores, os padrões de sociabilidade e os modos de subjetivação na sociedade contemporânea também impõem sérias limitações ao trabalho em saúde e a sua qualidade.

De outro lado, o reconhecimento da dimensão intersubjetiva das organizações e do trabalho em saúde, implica, considerando a perspectiva teórica aqui adotada ${ }^{2}$, o reconhecimento de sua dimensão inconsciente e, sobretudo, de que esta produz efeitos (para o bem ou para o mal) sobre a qualidade do cuidado (Sá, 2005).

\section{Problematizando a perspectiva de "humanização" das práticas de saúde ${ }^{3}$}

Em algumas áreas da assistência, o "discurso" da humanização encontra-se mais elaborado e algumas práticas já instituídas, como a assistência ao parto e neonatal de risco, assim como a assistência a pacientes com câncer e a pacientes terminais. Outras áreas, no entanto, como a assistência na rede básica de serviços de saúde, só mais recentemente vêm sendo alvo de intervenções com este tipo de preocupação, destacando-se as iniciativas bem-sucedidas de adoção do acolhimento como um dispositivo favorecedor da reestruturação das práticas de saúde (Franco et al., 2004; Sergipe, 2004; Franco et al., 2003).

As propostas voltadas para os hospitais gerais e, especialmente, para o atendimento de urgência e emergência, salvo experiências isoladas, ainda são mais recentes. Nesses hospitais se concentram desafios importantes para a humanização da assistência, tanto pela natureza dos problemas que ali chegam, como pelas condições adversas de trabalho e pela sobrecarga da demanda (Sá et al., 2008; Sá,

\author{
2 Orientada \\ fundamentalmente pela \\ Psicossociologia francesa \\ (Enriquez, 1997, 1994a, \\ 1994b), pela teoria \\ psicanalítica sobre os \\ processos intersubjetivos \\ e grupais (Kaës, 1989) e \\ pela Psicodinâmica do \\ Trabalho (Dejours, 2004, \\ 1999). \\ ${ }^{3}$ Parte das avaliações \\ aqui desenvolvidas \\ baseia-se no material a \\ que tive acesso \\ enquanto membro da \\ Comissão Nacional de \\ Avaliação do Prêmio \\ David Capistrano da \\ Política Nacional de \\ Humanização- \\ HumanizaSUS - \\ instituído, em 2004, \\ pelo Ministério da \\ Saúde. Tratava-se de um \\ conjunto de 671 \\ projetos candidatos ao \\ prêmio. É importante \\ ressaltar que 0 \\ julgamento que aqui \\ faço expressa apenas \\ minha posição pessoal \\ sobre os projetos, dos \\ quais pude examinar \\ diretamente cerca de \\ $20 \%$, obtendo \\ informações do conjunto \\ nas reuniões da \\ Comissão.
}


2005). Nesses serviços, a ética da "comunicação" e do "reconhecimento do outro", já naturalmente frágil, tem muito mais chances de fracassar.

Além das diferenças quanto ao grau de institucionalização das práticas, algumas experiências consideradas de "humanização" da assistência ainda parecem apresentar um caráter muito pontual e periférico em relação aos serviços de saúde onde se desenvolvem e às lógicas de organização de seus processos de trabalho, não conseguindo impactá-los. Observam-se "comitês de humanização" ou núcleos de Recursos Humanos, cujas principais atividades ainda se concentram na criação de espaços periféricos de entretenimento e confraternização. Algumas experiências guardam um caráter centralmente filantrópico, operando apenas com doações e/ou dependentes exclusivamente de trabalho voluntário, o que ainda está muito distante dos ideais de direitos de cidadania e da ética da "alteridade" presentes no discurso da "humanização".

Grande parte das propostas de intervenção voltadas para as interações entre profissionais e usuários geralmente não vai além de recomendações sobre a necessidade do desenvolvimento de uma ética pautada: no reconhecimento do outro, no acolhimento, na responsabilização e no estabelecimento de vínculos, na cooperação e na valorização da comunicação; sem problematizar, no entanto, quais seriam os possíveis condicionantes da produção ou ausência desta ética, limitando-se, consequentemente, em sua capacidade de proposição de ações ou mecanismos que a favoreçam.

Mesmo estratégias mais específicas, como a capacitação dos profissionais e a criação ou ampliação de mecanismos de comunicação, embora condições imprescindíveis, não são suficientes. A disposição para o acolhimento, para a escuta e para o estabelecimento de vínculos não se constitui em uma capacidade absoluta e apriorística do ser humano ou em algo que possa ser controlado exclusivamente por um trabalho consciente e voluntário e/ou por mecanismos gerenciais.

Por parte do Ministério da Saúde, a questão da humanização da assistência vem recebendo, sem dúvida, atenção crescente, destacando-se a iniciativa, em 2001, do Programa Nacional de Humanização da Assistência Hospitalar - PNHAH (Brasil, 2001) e, sobretudo, a atual Política Nacional de Humanização (PNH) (Brasil, 2004).

É inegável o avanço conceitual e prático que a atual Política de Humanização do Ministério da Saúde representa comparativamente a iniciativas anteriores, buscando romper com a concepção de programa isolado, propondo-se como política transversal, construindo capilaridade para seus princípios nas diversas ações do SUS e em suas instâncias de gestão. O eixo norteador das ações de humanização também parece ter sofrido um deslocamento - vantajoso, acredito - da humanização vista como "ampliação do processo comunicacional" - de base hermenêutica gadameriana, diretriz central da proposta de humanização contida no Programa Nacional de Humanização da Assistência Hospitalar do MS de 2000 (Deslandes, 2004) - para a humanização como "produção de sujeitos autônomos", capazes de estabelecer vínculos solidários e corresponsabilidade na produção de ações de saúde e em sua gestão proposta fortemente inspirada na perspectiva da Análise Institucional e da Socioanálise de René Lourau (1995) e Georges Lapassade (1977), bem como na "filosofia da diferença", vinculada a Félix Guattari (1985) e Gilles Deleuze (Deleuze, Guattari, 1992), o que traz para a cena a importância da intervenção na micropolítica, na transformação das práticas e o peso dos poderes cotidianos e do "instituído" como limites ao exercício de uma comunicação idealizada como transparente e simétrica entre os sujeitos na produção de ações de saúde.

No entanto, a complexidade das questões relacionadas à "humanização" das práticas de saúde ainda impõe muitos desafios. A contraposição da idéia de "humanização" aos processos de discriminação, indiferença e desprezo pelo outro, apatia diante de seu sofrimento e todas as demais formas de violência que se verificam na sociedade - e, particularmente, nos serviços de saúde -, produz opacidade sobre o que talvez seja um dos principais nós críticos do problema, pois subtrai do que é humano o mal que também Ihe é inerente (Sá, 2005). Tal perspectiva se aproxima de uma das principais crenças veiculadas pela doutrina do Humanismo Cristão ou Personalismo Cristão: a de que o ser humano é bom (Minayo, 2004).

Assim, o problema principal com a utilização do termo "humanização" reside, acredito, na sua inadequação para designar o que pretende. Em consequência, correm o risco de equívoco algumas estratégias de intervenção baseadas nessas concepções. Se o ser humano é essencialmente bom, basta orientá-lo, educá-lo, "sensibilizá-lo" para o exercício desta "bondade" para com o próximo. 
Hoje, a despeito dos avanços de concepções e de práticas possibilitados pela $\mathrm{PNH}$, é preciso considerar que a metáfora da sociedade harmonizada, conciliada e transparente é muito insidiosa e sedutora e ainda parece informar algumas propostas "humanizantes". Assim, não só é preciso continuar a problematizar a natureza sociológica da impossibilidade de uma comunicação totalmente transparente e baseada numa simetria entre os sujeitos, conforme propôs Deslandes (2004), como é preciso problematizar a "natureza psicanalítica" (ou, aglutinando as duas perspectivas, a natureza "psicossociológica") desta impossibilidade. Destaca-se aqui a ambivalência que o sujeito apresenta em sua relação com o outro (Freud, 1976), visto simultaneamente como portador do bem e do mal, e a oscilação permanente do sujeito entre os polos narcísico e alteritário (Birman, 2000).

Onocko Campos (2004) desenvolve uma argumentação análoga, chamando a atenção para o fato de que a violência, a raiva, a inveja, as agressões são absolutamente humanas, e observa que, para lidarmos com estas questões, não nos basta o cogito cartesiano, posto que não somos apenas seres racionais.

Finalmente, não é possível deixar de problematizar os enormes desafios que os padrões de sociabilidade e subjetivação dominantes em nossa sociedade impõem às iniciativas de humanização, conformando um quadro extremamente adverso a práticas solidárias e de cuidado com o outro.

\section{A fraternidade: um projeto ainda possível na sociedade contemporânea?}

Temas como a cooperação, a humanização e o cuidado em saúde remetem à problemática da fraternidade. Segundo Birman (2000, p.184), a ética da fraternidade pressupõe, acima de tudo, a existência de um sujeito "incompleto e precário", que possa reconhecer que não é autossuficiente. No entanto, é justamente a autossuficiência do sujeito que caracteriza, como lembra o autor, o modelo de subjetivação contemporânea, promovido pela "cultura do narcisismo" e pela "sociedade do espetáculo".

No que concerne às práticas de saúde, penso que não seja possível, por exemplo, esperar que haja cooperação entre profissionais que se julgam autossuficientes com seus saberes e técnicas. A cooperação, a solidariedade e o cuidado dependem da disposição do sujeito para se "abrir" ao outro, para buscar no outro o que ele não sabe ou o que lhe falta. Do mesmo modo, não podemos esperar comportamentos solidários de sujeitos que não conseguem enxergar, no sofrimento e fragilidade do outro, a sua própria precariedade e insuficiência.

Como modalidade específica de produção e manifestação do laço social, a fraternidade só se torna possível com a emergência da sociedade moderna (Birman, 2000). Esta implicaria a instalação do igualitarismo dos agentes sociais, concebido a partir da figura do irmão, de forma que a ordem social moderna seria necessariamente uma ordem fraternal, diferenciando-se das sociedades pré-modernas, nas quais a fraternidade não se identificaria com o laço social, existindo hierarquias de diversas ordens. No entanto, paradoxalmente, a mesma modernidade engendra, na transição do século XVI para o século XVII, a formação ilusória da autossuficiência, contrapartida imaginária do humanismo, quando o homem foi alçado à condição de centro do mundo e medida de todas as coisas, desafiando e desalojando o poder divino, pela mediação da razão e da ciência (Birman, 2000). Tal processo

\footnotetext{
[...] conduziu o sujeito a um impasse marcado pela tragicidade: precisar do outro como um igual e um irmão para realizar a gestão do mal-estar produzido [...] pelo desamparo, contrapartida da Morte de Deus no nível antropológico; ou então acreditar na sua divinização narcísica centrada no eu, se agarrando ilusoriamente na sua auto-suficiência. (Birman, 2000, p.194)
}

Nesta perspectiva, o sujeito oscilaria, permanentemente, entre os polos narcísico e alteritário.

No mundo pós-moderno, a economia do desamparo em muito se incrementou, devido à perda de algumas utopias que fundavam o projeto modernista. Com isso, o ideário da fraternidade foi balançado em suas proposições e "[...] aparece hoje como uma espécie de sonho do passado sem mais qualquer lugar na atualidade" (Birman, 2000, p.204).

Diversos autores, do campo da Sociologia, da Filosofia ou da Psicanálise, vêm procurando 
compreender e buscar saídas para um conjunto de "sintomas" que põem em cheque, de modo aparentemente irreversível, o ideário da fraternidade.

Bauman (1998) destaca a total desregulamentação, a insegurança e o despedaçamento das antigas redes de solidariedade, caracterizando a situação de "incerteza radical" da vida pós-moderna. Enriquez (1994 a) aponta a intensificação do individualismo, em detrimento da efetiva valorização do sujeito, e a impossibilidade de ligação com os outros. Santos (1999) nos mostra como o individualismo possessivo e a cultura consumista produzem um desvio das energias sociais da interação com pessoas para a interação com objetos. Há uma supervalorização da dimensão econômica e uma obsessão pela modernização, junto com uma idealização da técnica e da tecnologia (Enriquez, 1994b).

O incremento da violência e a intensificação dos comportamentos perversos também compõem a dinâmica social contemporânea (Enriquez, 1994b). Dejours (1999) denuncia uma tolerância social cada vez maior para com as injustiças sociais e para com os sofrimentos infligidos a outrem em nossas sociedades, o que funcionaria como uma defesa contra a consciência dolorosa da própria cumplicidade e responsabilidade dos indivíduos no agravamento da adversidade social.

Costa (1989) chama a atenção para uma passagem gradual, na sociedade brasileira, de um ethos predominantemente centrado no público para um outro dirigido ao culto do privado e do indivíduo, cuja característica principal foi a desqualificação sistemática da política como meio de participação dos indivíduos na gestão do bem comum, por meio de uma "reviravolta imaginária" que fez da política e do Estado instituições acessórias, quando não parasitárias. Segundo o autor, vivemos numa cultura cínico-narcísica, que não se restringe às elites brasileiras, mas "abocanha" outras áreas da vida social com especial intensidade.

Um indicativo importante dessa cultura "cínico-narcísica" seria o refrão do "não tem jeito", "nada mais se deve esperar". A partir daí, não há qualquer possibilidade de se pensar em médio ou longo prazos (pré-condições, entendo, do planejamento e da gestão) ou qualquer possibilidade de preocupação (e cuidado, poderíamos dizer) com o outro. "Pouco importa o outro ou o amanhã: importa sobreviver hoje" (Costa, 1989, p.37).

O autor destaca, entre os processos que vêm progressivamente conformando o modelo de subjetivação das elites brasileiras, o alheamento em relação ao outro. (Costa, 2000). Ao contrário do ódio, da rivalidade ou do temor diante de um adversário que representa alguma ameaça, " $[$...] o alheamento consiste numa atitude de distanciamento, em que a hostilidade ou o vivido persecutório são substituídos pela desqualificação do sujeito como ser moral ${ }^{4 "}$ (Costa, 2000, p.79).

${ }^{4}$ Grifo do autor.

Nesta perspectiva, os pobres e miseráveis são cada vez menos percebidos como pessoas morais. Os desprezados não são vistos como adversários de classe ou de interesse, mas como uma espécie de "[...] resíduo social inabsorvível, com o qual se deve aprender a conviver [...]" (Costa, 2000, p.80).

Neste contexto, é preciso coragem e sabedoria para propor uma "humanização" dos serviços/das práticas de saúde. Coragem, em primeiro lugar, para assumir, em sua radicalidade, o que, acredito, a idéia de "humanização" em saúde sugere: trazer, para o centro das questões a serem enfrentadas pela gestão dos serviços de saúde, tudo o que do humano é manifestação ou produto, para o bem ou para o mal. Coragem, em segundo lugar, para sustentar a importância das utopias como uma das saídas fundamentais para os problemas da sociedade contemporânea. Sabedoria para não se deixar aprisionar pelas armadilhas da cegueira voluntarista/onipotente e ser capaz de construir e reconstruir, cotidianamente, com o conhecimento e a experiência da realidade, aproximações possíveis (e sempre provisórias) aos projetos utópicos. 


\section{O trabalho em saúde e suas exigências de trabalho psíquico: desafios para a produção do cuidado}

Embora reconhecendo que a organização da estrutura assistencial em saúde e das práticas em saúde seja um processo histórico-social com múltiplas determinações (Pires, 1998), acredito que podemos falar de uma "essência" ou de uma especificidade do trabalho em saúde, que o diferencia dos demais trabalhos humanos e que se "preserva", ao longo das diversas transformações a que historicamente vem sendo submetido.

Tal especificidade, de um lado, Ihe é dada por seu próprio objeto que, entendo, não são as doenças, de um modo geral - objeto das ciências e saberes que apoiam a Medicina - mas a vida, o prazer, a dor, o sofrimento, a morte em suas manifestações singulares no corpo e na alma (no psiquismo) de cada sujeito. De outro lado, a especificidade do trabalho em saúde advém de seu "que fazer". Trata-se, como observa Schraiber (1993) a respeito do trabalho do médico, de um trabalho de intervenção de um homem sobre outro, destacando, portanto, o seu aspecto relacional, intersubjetivo, e lembrando também que "[...] se está diante de uma 'invasão', ainda que permitida, do outro: interferência sobre as vidas, as privacidades e as paixões das pessoas" (Schraiber, 1993, p.150).

Estou adotando aqui uma visão do trabalho em saúde mais próxima à sua dimensão assistencial ou clínica, não contemplando adequadamente objetos e afazeres de outras práticas também reconhecidas socialmente como trabalho em saúde, mas que não pressupõem uma relação direta com (e uma intervenção ou manipulação direta sobre) indivíduos singulares. Retenho, como essência do trabalho em saúde, a sua característica relacional/intersubjetiva e de intervenção de um sujeito sobre outro porque acredito que seja esse o espaço (da ordem do singular), por excelência, da possibilidade de exercício da solidariedade, da cooperação e do cuidado com a vida, mas também, paradoxalmente, o espaço privilegiado para o exercício de comportamentos perversos, para o descuido, enfim, para a produção do mal nos serviços de saúde.

Todos os fenômenos que constituem o objeto do trabalho em saúde, além de sua base biológica, conformam uma experiência, uma vivência, algo, portanto, da ordem do singular, dos processos subjetivos. Apoio-me aqui na discussão realizada por Dejours (1999) a respeito do conceito de sofrimento. Com base na fenomenologia alemã, Dejours conceitua o sofrimento como uma "experiência vivenciada", um estado mental que implica um movimento reflexivo da pessoa sobre seu "estar no mundo". Tal vivência, todavia - considerada também numa perspectiva psicanalítica - não é totalmente consciente. Tem sempre uma parte inapreensível, desconhecida e, até mesmo, não representável.

Referindo-se ao modo peculiar como o caráter científico se inscreve na prática médica, onde se trata de "conectar" a doença (o conhecimento científico advindo da patologia) ao doente, à sua singularidade, Schraiber observa que "o médico se dá conta de, e sabe que deve levar em conta, a totalidade singular do doente" (Schraiber, 1993, p.165).

Portanto, podemos entender que o trabalho em saúde se realiza sobre uma "totalidade singular" e, por sua vez, enquanto intervenção, constitui-se como um ato sempre "único", dependente do encontro de duas subjetividades, a do paciente e a do profissional, esta última manifesta na sua capacidade de julgamento - para aplicar o saber, a técnica, operar intervenções, como observa Schraiber (1993) - na sua experiência, na sua criatividade e valores morais.

Do exposto até aqui, é possível concluir que a especificidade do trabalho em saúde, ou o que constitui sua essência, é sua característica intersubjetiva e de intervenção única de um sujeito sobre outro, em suas experiências singulares de vida, prazer, dor, sofrimento e morte. O caráter mais ou menos técnico-científico deste trabalho, seu grau de especialização, sua forma/lógica de organização e de divisão técnica e social, suas finalidades, bem como as representações e valores a ele associados é que irão, obviamente, variar nos diferentes contextos histórico-sociais, alargando ou estreitando as margens da solidariedade e do cuidado com a vida.

Esta compreensão apresenta, pelo menos, três consequências ou implicações importantes:

1) A dimensão intersubjetiva do trabalho em saúde não pode ser dissociada dos demais componentes deste trabalho (tecnologias, saberes etc). Schraiber (1993) e Merhy (2002) já o demonstraram: ela não só é condição de eficácia do trabalho em saúde como lhe é central, essencial. 
Conforme observa Teixeira (2003), apesar " [...] das entusiásticas promessas da biomedicina triunfalista [...] parece que a coisa não funciona mesmo muito bem sem este outro, chamado paciente, entre aspas [...]" (Teixeira, 2003, p.92).

2) Por se tratar de "trabalho vivo em ato" (Merhy, 2002, p.45), penso que esta dimensão intersubjetiva do trabalho em saúde seja aquilo que, deste trabalho, mais escapa às estratégias de controle gerencial, o que nos impõe imensos desafios, do ponto de vista da gestão, para a garantia de qualidade das ações produzidas.

3) Considerando que os homens não veem seus semelhantes apenas como um apoio, fonte de conforto ou modelo sobre o qual constroem suas identidades, mas também como fonte de perigos, ameaça ou possibilidade de morte (Freud,1976), entendo que o trabalho em saúde, pela centralidade de sua dimensão intersubjetiva, é altamente exigente de trabalho psíquico, compreendido como a produção de processos e formaç̧̃es inconscientes (Kaës, 1989), como as estratégias defensivas, as fantasias, as ilusões, as alianças inconscientes, as identificações e idealizações. Estas podem ser positivas, com relação ao outro e ao trabalho, por exemplo, mas também podem expressar o desejo de domínio, a inveja, os ataques ao vínculo, a negação do outro, ou sua representação como mero objeto de gozo, destituído de subjetividade. Isto significa dizer que o trabalho psíquico empreendido pelos profissionais de saúde (individual ou coletivamente) na realização de seu trabalho produz efeitos sobre a qualidade do cuidado em saúde.

Acredito que o modo como os sujeitos responderão às exigências de trabalho psíquico impostas pelo trabalho em saúde depende da articulação de suas histórias individuais com as do conjunto intersubjetivo - do coletivo de trabalho ou das organizações - onde se inserem, condicionando favorável ou desfavoravelmente a produção do cuidado. Do mesmo modo, essas exigências podem ser intensificadas pelas condições materiais e pelo contexto organizacional e social em que o trabalho em saúde se realiza, com impactos na dinâmica "prazer-sofrimento" no trabalho (Dejours, 2004) e, igualmente, nas formas de organização e realização do trabalho.

\section{Algumas possibilidades de análise e de abordagem da dimensão intersubjetiva e inconsciente do trabalho em saúde e suas implicações sobre a qualidade do cuidado}

Se o reconhecimento da centralidade da dimensão intersubjetiva do trabalho em saúde obriga a gestão a reconhecer seus limites de intervenção e de controle diretos sobre aquilo que se passa no trabalho "vivo em ato" (Merhy, 2002, p.45) - no momento "entre-dois" em que o trabalho em saúde se produz e se consome - o reconhecimento de que parte dos processos intersubjetivos que ali se dão são da ordem do inconsciente, isto é, daquilo a que os sujeitos não só não controlam como não têm acesso diretamente pela via da razão, obriga-nos a uma postura muito mais humilde com relação às possibilidades de mudança das práticas de saúde.

No entanto, o fato de não controlarmos uma boa parte desses processos não nos isenta de responsabilidade pelas consequências negativas que os mesmos eventualmente possam apresentar sobre a qualidade do cuidado, nem nos exime da responsabilidade de propor e tentar mudanças.

Kehl (2002), ao discutir a questão da ética, a partir da Psicanálise, recupera a discussão realizada por Freud em "A responsabilidade moral pelo conteúdo dos sonhos", em que o autor observa que, embora não o controle, não pode deixar de reconhecer como parte de si mesmo e de se responsabilizar, em consequência, por seu inconsciente.

Responsabilidade difícil de assumir esta - pelo estranho que existe em nós, age em nós e com o qual não queremos nos identificar. No entanto, eticamente, é preferível que o sujeito arque com as conseqüências dos efeitos do seu inconsciente, fazendo deles o início de uma investigação sobre o seu desejo, a que ele permita que tais efeitos se manifestem apenas na forma do sintoma. Ou, o que é ainda mais grave, que o sujeito tente se desembaraçar do inconsciente, por meio dos atos de intolerância que projetam no outro o que o eu não quer admitir em si mesmo. (Kehl, 2002, p.32) 
Coloca-se, então, uma dupla tarefa para que possamos avançar na proposição e nas tentativas de implementação de mudanças nas práticas de saúde (para além dos necessários esforços de reorganização e melhoria das condições e dos processos de trabalho). De um lado, explorar, buscar (re)conhecer, os processos intersubjetivos/inconscientes presentes no modo como se realiza o trabalho em saúde e suas consequências sobre a qualidade do cuidado. De outro lado, buscar, propor e/ou fortalecer dispositivos e processos de gestão e organização do trabalho que favoreçam a gestores e trabalhadores de saúde o acesso a sua própria subjetividade - ao (re)conhecimento das fontes de seu sofrimento e prazer no trabalho, dos vínculos imaginários/afetivos que os ligam ao trabalho, às organizações, ao outro (profissional, usuário) e do sentido do trabalho em suas vidas.

Nesta perspectiva, alguns processos e produções abaixo indicados podem ser tomados como possíveis elementos de análise e, também, de abordagem/intervenção por meio da gestão em saúde.

1 A dinâmica prazer-sofrimento no trabalho: a análise da relação entre prazer e sofrimento no trabalho e das estratégias de defesa dos trabalhadores contra o sofrimento no trabalho (Dejours, 2004, 1999) revela importantes condicionantes das possibilidades e, também, dos limites do cuidado. $O$ trabalho em saúde apresenta muitas fontes de sofrimento (Pitta, 1999; Silva, 1994).

A especificidade de alguns desses processos e suas consequências sobre a qualidade do cuidado foram estudadas em um hospital de emergência no Rio de Janeiro (Sá, 2005). Ali se destacam, entre outras fontes de sofrimento, a pressão da demanda e a pressão para trabalhar mal; as angústias ante a possibilidade de não identificar e intervir a tempo nos casos graves e de risco de morte; a violência, sob a forma de mortes e corpos mutilados pela "guerra" urbana e, também, por meio do ataque da população. Este sofrimento é vivenciado e se manifesta de diferentes modos, no conjunto de trabalhadores, incluindo tanto quadros já conformados como de "doenças profissionais", como formas difusas de malestar e de expressão de uma demanda significativa por reconhecimento, escuta e cuidado.

Do mesmo modo, são várias as defesas individuais e coletivas buscadas pelos trabalhadores para o sofrimento (Sá, 2005), a exemplo das brincadeiras, da negação da situação adversa, da apatia ou indiferença, de certos modos ou rotinas de organização do trabalho, geralmente sob a forma dos jeitinhos/"transgressões" ou quebra-galhos", do zelo (Dejours, 1999) ou, mesmo, a idealização do trabalho.

As estratégias coletivas de defesa contra o sofrimento no trabalho têm um papel paradoxal (Dejours, 1999). Estas não têm apenas um impacto no funcionamento psíquico singular, evitando que os trabalhadores enlouqueçam a despeito das pressões que enfrentam, mas têm um papel essencial na própria estruturação dos coletivos de trabalho, na sua coesão. Por outro lado, essas defesas também "[...] podem funcionar como uma armadilha que insensibiliza contra aquilo que faz sofrer. Além disso, permitem às vezes tornar tolerável o sofrimento ético [experimentado pelo sujeito por infligir a outrem um sofrimento por causa de seu trabalho] e não mais apenas psíquico" (Dejours, 1999, p.36).

Um outro elemento de análise e intervenção fundamental na relação prazer-sofrimento no trabalho diz respeito à dinâmica do reconhecimento. A possibilidade de transformação do sofrimento em prazer no trabalho passa pelo reconhecimento. Aqui, a gestão, o modo de se fazer a gestão, tem muitas possibilidades de intervenção. Segundo Dejours (2004), o reconhecimento no campo do trabalho exige uma formação da ordem do coletivo - coletivo, equipe ou comunidade de filiação, e é compreendido em dois sentidos: reconhecimento como gratidão pelas contribuições proporcionadas pelos trabalhadores no ajustamento da organização do trabalho; reconhecimento como conhecimento, constatação, revelação das contribuições dos trabalhadores à organização, sem as quais a organização do trabalho prescrito não chegaria a bom termo.

20 imaginário (Giust-Desprairies,2002; Enriquez,1997), que aqui defino como imagens, metáforas, fantasias, modos de representação psíquica compartilhados pelos profissionais sobre o serviço de saúde, sobre o trabalho e sobre o outro (paciente/população atendida).

Examinar, explorar, poder discutir as imagens/representações e metáforas que circulam nos serviços de saúde sobre o serviço, o trabalho, ou a população atendida pode ajudar a identificar e compreender os tipos de vínculo existentes entre os trabalhadores, entre estes e os serviços, e entre trabalhadores de 
saúde e a população. Tais produções imaginárias cumprem funções específicas no psiquismo dos trabalhadores e produzem, igualmente, efeitos (positivos ou negativos) sobre a qualidade do cuidado.

Assim, por exemplo, imagens que associam a organização à "casa", à "família", a uma "escola" (Sá, 2005) podem estar atendendo a demandas (psíquicas) dos trabalhadores de proteção, de amparo, de potência, diante de uma realidade tão adversa em termos de condições materiais e tecnológicas, ou ainda, num contexto de baixa cooperação e responsabilização e de precariedade das relações de trabalho, podem estar alimentando a ilusão da "doçura comunitária", da cooperação idealizada (Sá, 2005).

Um outro trabalho (Sá et al., 2008) demonstra que a utilização generalizada, pelos trabalhadores de um hospital, da categoria "carência" para representar a população parece exercer uma função psíquica de encobrimento da violência simbólica à qual a população é cotidianamente submetida naquele serviço de saúde. Tal encobrimento, produto de uma aliança inconsciente (Kaës, 1997) entre os trabalhadores, teria a função de poupá-los do reconhecimento dessa violência.

Em outro exemplo, Azevedo et al. (2007) destacam, em estudo com diretores de hospitais públicos, algumas funções cumpridas pelo imaginário na conformação de determinadas modalidades de prática gerencial.

\section{Os processos de identificação}

Cuidar pressupõe olhar o outro, um olhar sobre o outro. A disposição para olhar o outro (e a possibilidade de reconhecer, no outro e em seu sofrimento, algo de si mesmo) não se distribui uniformemente entre os diversos trabalhadores de saúde de um mesmo serviço e tampouco se manifesta de um mesmo modo para um mesmo sujeito, a cada dia e diante de cada caso. Tal disposição depende, em grande medida, do processo de identificação que se estabelece entre o trabalhador e o sujeito de quem deve cuidar, a quem deve assistir. Trata-se de um processo de "mão dupla", isto é, que se dá na/e pela intersubjetividade.

A formulação freudiana do conceito de identificação, o define como "[...] a mais remota expressão de um laço emocional com outra pessoa" (Freud, 1976, p.133), processo central por meio do qual o sujeito - produto de múltiplas identificações - se constitui e se transforma (Roudinesco, Plon, 1998; Laplanche, Pontalis, 1986).

No que se refere ao cuidado em saúde, julgo importante investigar a identificação como um processo que " [...] pode surgir com a percepção de uma qualidade comum partilhada com alguma outra pessoa que não é objeto de

${ }^{5}$ Considerando a opção de tradução na Standard Edition de trieb por instinct, mantida na edição brasileira (GarciaRoza, 1983), cabe aqui entender pulsão sexual ou "investimento sexual", este último presente em Laplanche e Pontalis (1986) e em Roudisnesco e Plon (1998) no verbete "identificação". instinto sexual ${ }^{5 "}$ (Freud, 1976, p.136), ou como "[...] produto da "capacidade ou [da] vontade de colocar-se numa situação idêntica' à do outro ou dos outros" (Roudisnesco, Plon, 1998, p.364).

Em grande parte dos serviços públicos de saúde no Brasil, onde a precariedade das vidas e o desamparo da população toma, frequentemente, a forma de sujeira, dos maus-tratos, da fome, da feiura e, às vezes, da agressividade (Sá et al., 2008; Sá, 2005), encontram-se extremamente reduzidas as margens para o desenvolvimento de processos de identificação positivos, por parte dos trabalhadores para com os pacientes. O que predomina é a apatia e a indiferença (por vezes, uma estranheza radical) em relação ao outro (Sá et al., 2008; Sá, 2005).

No entanto, a despeito do peso desses processos, alguns olhares e cuidados ainda são possíveis. E aqui a identificação se coloca como processo central tanto para a possibilidade de percepção do sofrimento alheio, como para a mobilização contra o mesmo. Segundo Dejours (1999a), a percepção do sofrimento alheio não diz respeito apenas a um processo cognitivo. Implica, também, uma participação 
"pática" do sujeito que percebe, para dar origem a uma reação contra o mesmo. A mobilização contra o sofrimento depende, portanto, não apenas da inteligibilidade do drama vivido pela vítima, mas também da comoção das testemunhas, isto é, dos meios empregados para a produção do sofrimento nas testemunhas, Ihes despertando compaixão (Dejours, 1999a). Esta compreensão abre algumas perspectivas interessantes para refletirmos sobre as estratégias pedagógicas de formação e educação continuada, assim como de supervisão e gestão das equipes de saúde.

\title{
4 Os processos grupais
}

Por fim, embora os limites do presente artigo não permitam um maior desenvolvimento deste ponto, cabe ressaltar que todos os processos acima destacados são produzidos nos - e podem ser apreendidos e abordados por meio dos - processos grupais. Os grupos são uma importante instância de análise e intervenção das organizações (Enriquez, 1997) e devem ser considerados para além de suas fronteiras formais ou dos processos racionais e dos objetivos que justificam sua criação. As equipes, os grupos de trabalho, os coletivos ou instâncias colegiadas são também dispositivos de expressão (e podem ser, também, dispositivos de encaminhamento, por intermédio da gestão) dos processos intersubjetivos inconscientes (Kaës, 1989), das dimensões imaginária e simbólica que atravessam as organizações e produzem importantes efeitos na qualidade do trabalho ali produzido.

\section{Considerações finais ou Quíron e a busca de outros modos de produzir a gestão (do cuidado) em saúde}

\author{
Conta a lenda que a arte de curar foi ensinada por Apolo ao centauro Quíron. Este, por sua \\ vez, a transmitiu a Esculápio, o deus da medicina. Com Quíron, Esculápio aprendeu a \\ praticar a cura pelas ervas. Entretanto, Quíron tinha uma ferida que jamais cicatrizava: ele \\ vivia curando os outros mas estava sempre doente, sempre sofrendo, e por isso era capaz de \\ compreender os sofrimentos daqueles a quem tratava. (São Paulo, 2002, p.20)
}

O mito grego do "curador ferido" é uma interessante e sábia alegoria do cuidado e dos processos nele envolvidos. Com ela, podemos vislumbrar a indicação de alguns possíveis caminhos para o enfretamento, no âmbito da gestão, do imenso desafio que é a mudança das práticas de saúde orientada pelos valores de fraternidade, solidariedade e cuidado com o outro.

Um desses caminhos se faz justamente trazendo o cuidado para o centro da gestão em saúde, o que compreende duas perspectivas. Uma delas diz respeito à garantia do cuidado com a vida no modo de produzir o cuidado em saúde. Tal perspectiva significa, sobretudo, ter, como preocupação central, a garantia das condições materiais, tecnológicas, humanas e organizacionais necessárias à escuta e ao acolhimento das demandas por cuidado que os sujeitos trazem aos serviços de saúde, bem como à eliminação ou (quando isto não for tecnicamente possível) à redução ao mínimo de seus sofrimentos.

A outra perspectiva diz respeito à garantia de cuidado com o outro no modo de produzir a gestão em saúde. Tal perspectiva significa trazer para o centro das preocupações da gestão em saúde os processos intersubjetivos presentes nas organizações de saúde. Não se trata de desviar o olhar dos temas e problemas tradicionalmente tratados pela gestão, mas iluminá-los a partir de lentes capazes de focalizar os efeitos desses processos sobre a organização e, particularmente, sobre o trabalho em saúde, sobre a capacidade de autonomia e de responsabilidade dos trabalhadores, e, consequentemente, de cooperação e construção coletiva.

Mudanças nos processos organizacionais envolvem a conjunção entre a história dos grupos/ coletividades e a dos indivíduos que os integram. O espaço dos serviços de saúde não é só um espaço material, normativo e político, mas um espaço interpsíquico: o modo como está organizado este universo simbólico e imaginário compartilhado pelos sujeitos nos serviços condiciona sua capacidade de escuta e resposta às demandas da população, bem como as possibilidades de mudança das práticas de saúde. 
Azevedo et al. (2007), em analogia à leitura de Merhy (2002) sobre a natureza do trabalho em saúde, tratam a gestão e o trabalho gerencial como "trabalho vivo em ato", que se realiza entre sujeitos. Para as autoras, o desencadeamento de processos de mudança pressupõe o favorecimento da maior circulação da palavra e autonomia dos sujeitos, e a busca de novos sentidos para o trabalho que possibilitem abrir brechas no imaginário organizacional dominante.

Trata-se, portanto, de buscar outros modos de se fazer gestão em saúde. Na perspectiva clínica psicossociológica (Giust-Desprairies, 2001), trata-se de desenvolver capacidade de escuta (e de resposta ou encaminhamento) do sofrimento (não só dos pacientes, mas igualmente dos trabalhadores/gestores) e das demandas por sentido que atravessam a vida organizacional.

\begin{abstract}
Trabalhar na compreensão das lógicas internas das pessoas e dos grupos, em suas ligações com as lógicas internas das organizações, implica necessariamente levar em conta os componentes subjetivos. Portanto, a questão do sentido não diz respeito somente ao privado ou individual, ela também se refere ao social. (Giust-Desprairies, 2001, p.231)
\end{abstract}

A responsabilidade dos gestores, para ser responsabilidade pelos gastos públicos, tem de ser, antes, responsabilidade para com o outro. A responsabilidade para com o outro é a essência do cuidado e, igualmente, a base para a solidariedade e para a cooperação.

Para que possamos, no entanto, ser responsáveis para com o outro, precisamos ser responsáveis, como vimos (Kehl, 2002), pelos nossos próprios desejos e pelo nosso conflito psíquico. Precisamos ter acesso ao nosso próprio sofrimento, e aqui o Mito de Quíron pode ser uma referência tanto para os profissionais da assistência como para os gestores.

Analogamente ao papel do pesquisador destacado por Lèvy (2001), penso que a gestão deva se constituir num trabalho de provocação, por intermédio do qual o gestor provoca, por sua presença e por suas palavras, os trabalhadores a falarem e a discutirem a respeito de suas experiências ou daquilo que elas possam evocar ou significar para eles. Um trabalho contra o empobrecimento, denunciado por Birman (2003), do espaço social pela redução do discurso à sua dimensão informacional/instrumental, em detrimento da metáfora, da capacidade de simbolização. Ou ainda, acredito, um trabalho, sempre provisório, de mediação. Mediação entre as lógicas subjetivas, grupais, organizacionais. Mediação entre dor e sofrimento - entendida, com Birman (2003), a primeira como uma experiência solipsista, onde o sujeito dobra-se sobre si mesmo, encerrado nos murmúrios do negacionismo impotente, e a segunda como uma experiência alteritária, que possibilita a busca do outro, dirigindo-Ihe um apelo, uma demanda, ou lançando o sujeito no mundo intersubjetivo do trabalho (Dejours, 1999) e da fraternidade e, consequentemente, na possibilidade de construção de projetos coletivos.

\title{
Referências
}

AZEVEDO, C.; FERNANDES, M.I.A.; CARRETEIRO, T.C. Sob o domínio da urgência: a prática de diretores de hospitais públicos do Rio de Janeiro. Cad. Saude Publica, v.23, n.10, p.2410-20, 2007.

BAUMAN, Z. O mal-estar na pós-modernidade. Rio de Janeiro: Zahar, 1998.

BIRMAN, J. Dor e sofrimento num mundo sem mediação. In: ENCONTRO MUNDIAL ESTADOS GERAIS DA PSICANÁLISE, 2., 2003, Rio de Janeiro. Anais... Disponível em: $<$ http://www.estadosgerais.org/mundial_rj/download/ 5c_Birman_02230503_port.pdf>. Acesso em: 5 nov. 2008. Insuficientes, um esforço a mais para sermos irmãos! In: KEHL, M.R. (Org.). Função fraterna. Rio de Janeiro: Relume Dumará, 2000. p.171-208. 
BRASIL. Ministério da Saúde. Manual do Programa Nacional de Humanização da Assistência Hospitalar. 2001. Disponível em: <http://www.humaniza.org.br. Acesso em: 20 maio. 2005.

Ministério da Saúde. Secretaria Executiva. Humaniza SUS: Política Nacional de Humanização - documento base para gestores e trabalhadores do SUS. Brasília: Ministério da Saúde, 2004.

COSTA, J. Por uma questão de vergonha: psicanálise e moral. São Paulo: Educ, 1989.

A ética democrática e seus inimigos. In: ROITMAN, A. (Org.). O desafio ético. Rio de Janeiro: Garamond, 2000. p.77-89.

DEJOURS, C. Parte I: trajetória teórico-conceitual; parte II: a clínica do trabalho; parte III: perspectivas. In: LANCMAN, S.; SZNELWAR, L.I. (Orgs.). Cristophe Dejours: da Psicopatologia à Psicodinâmica do Trabalho. Rio de Janeiro: Fiocruz, 2004. p.47-334.

DELEUZE, G.; GUATTARI, F. O que é Filosofia? São Paulo: Editora 34, 1992.

DESLANDES, S.F. Análise do discurso oficial sobre a humanização da assistência hospitalar. Cienc. Saude Colet., v.9, n.1, p.7-14, 2004.

1999.

A banalização da injustiça social. Rio de Janeiro: Fundação Getúlio Vargas,

ENRIQUEZ, E. A organização em análise. Petrópolis: Vozes, 1997.

A interioridade está acabando? In: LÉVY, A. et al. (Orgs.). Psicossociologia:

análise social e intervenção. Petrópolis: Vozes, 1994a. p.41-55.

O fanatismo religioso e político. In: LÉVY, A. et al. (Orgs.). Psicossociologia:

análise social e intervenção. Petrópolis: Vozes, 1994b. p.70-83.

FRANCO, T.B.; BUENO, W.S.; MERHY, E.E. O acolhimento e os processos de trabalho em saúde: o caso de Betim (MG). In: MERHY, E.E. et al. (Orgs.). O trabalho em saúde: olhando e experienciando o SUS no cotidiano. São Paulo: Hucitec, 2003. p.37-54.

FRANCO, T.B.; PANIZZI, M.; FOSCHIERA, M. O 'acolher Chapecó' e a mudança do processo de trabalho da rede básica de saúde. Divulg. Saude Debate, n.30, p.30-35, 2004.

FREUD, S. Psicologia de grupo e análise do ego. Rio de Janeiro: Imago, 1976. (Obras Completas de Sigmund Freud, 18)

GARCIA-ROZA, L.A. Freud e o inconsciente. Rio de Janeiro: Zahar, 1983.

GIUST-DESPRAIRIES, F. Representatión et imaginaire. In: BARUS-MICHEL, J.; ENRIQUEZ, E.; LÈVY, A. (Orgs.). Vocabulaire de psychosociologie: références et positions. Paris: Érès, 2002. p.231-50.

O acesso à subjetividade: uma necessidade social. In: ARAÚJO, J.N.G.; CARRETEIRO, T.C. (Orgs). Cenários sociais e abordagem clínica. São Paulo: Escuta, 2001. p.231-44.

GUATTARI, F. Revolução molecular: pulsações políticas do desejo. 2.ed. São Paulo: Brasiliense, 1987.

KAËS, R. O grupo e o sujeito do grupo: elementos para uma teoria psicanalítica do grupo. São Paulo: Casa do Psicólogo, 1989.

KEHL, M.R. Sobre ética e psicanálise. São Paulo: Companhia das Letras, 2002.

LAPASSADE, G. Grupos, organizações e instituições. Rio de Janeiro: Francisco Alves, 1977.

LAPLANCHE, J.; PONTALIS, J-B. Vocabulário da psicanálise. 9.ed. São Paulo: Martins Fontes, 1986. 
LÈVY, A. Ciências clínicas e organizações sociais. Belo Horizonte: Autêntica/FUMEC, 2001.

LOURAU, R. A análise institucional. Petrópolis: Vozes, 1995.

MERHY, E.E. Saúde: a cartografia do trabalho vivo. São Paulo: Hucitec, 2002.

MINAYO, M.C.S. Dilemas do setor saúde diante de suas propostas humanistas. Cienc. Saude Colet., v.9, n.1, p.17-20, 2004.

ONOCKO CAMPOS, R. Mudando os processos de subjetivação em prol da humanização da assistência. Cienc. Saude Colet., v.9, n.1, p.23-5, 2004.

PIRES, D. Reestruturação produtiva e trabalho em saúde no Brasil. São Paulo: CUT/ Annablume, 1998.

PITTA, A. Hospital: dor e morte como ofício. 4.ed. São Paulo: Hucitec, 1999.

ROUDINESCO, E.; PLON, M. Dicionário de psicanálise. Rio de Janeiro: Zahar, 1998.

SÁ, M.C. Em busca de uma porta de saída: os destinos da solidariedade, da cooperação e do cuidado com a vida na porta de entrada de um hospital de emergência. 2005. Tese (Doutorado) - Instituto de Psicologia, Universidade de São Paulo, São Paulo. 2005.

SÁ, M.C; CARRETEIRO, T.C.; FERNANDES, M.I.A. Limites do cuidado: representações e processos inconscientes sobre a população na porta de entrada de um hospital de emergência. Cad. Saude Publica, v.24, n.6, p.1334-43, 2008.

SANTOS, B.S. Pela mão de Alice: o social e o político na pós-modernidade. 5.ed. São Paulo: Cortez, 1999.

SÃO PAULO. Prefeitura Municipal. Secretaria Municipal de Saúde. Acolhimento: o pensar, o fazer, o viver. São Paulo: SMS, 2002.

SCHRAIBER, L.B. O médico e seu trabalho: limites da liberdade. São Paulo: Hucitec, 1993.

SERGIPE. Prefeitura Municipal de Aracaju. Secretaria Municipal de Saúde. Acolhimento enquanto tecnologia de garantia de acesso e organização do processo produtivo nas Unidades Básicas de Saúde. Experiência premiada pelo Ministério da Saúde, com o Prêmio David Capistrano da Política Nacional de Humanização - Humaniza SUS, instituído em 2004. (Mimeogr.).

SILVA, C.O. Curar adoecendo: um estudo do processo de trabalho hospitalar em busca da saúde, da inventividade e da vida. 1994. Dissertação (Mestrado) - Escola Nacional de Saúde Pública, Fundação Oswaldo Cruz, Rio de Janeiro. 1994.

TEIXEIRA, R.R. O acolhimento num serviço de saúde entendido como uma rede de conversações. In: PINHEIRO R.; MATTOS, R.A. (Orgs.). Construção da Integralidade: cotidiano, saberes e práticas em saúde. Rio de Janeiro: UERJ/IMS/Abrasco, 2003. p.89-111. 
SÁ, M.C. La fraternidad en cuestión: una mirada psico-sociológica al cuidado y la "humanización" de las prácticas de salud. Interface - Comunic., Saude, Educ., v.13, supl.1, p.651-64, 2009.

El presente artículo se propone discutir algunos desafíos a la producción del cuidado en salud considerando los procesos inter-subjetivos e inconscientes que lo condicionan. El planteamiento metodológico del análisis se apoya en categorías teóricas de la Psicosociología francesa, de la teoría psicoanalítica sobre los procesos inter-sujetivos/ grupales y de la Psico-dinámica del Trabajo. Los padrones de sociabilidad y los modos de subjetividad dominantes en la sociedad imponen serias limitaciones al trabajo en salud que se suman a las de orden material, tecnológica u organizativa más facilmente reconocidas. La dimensión inter-sujetiva/inconsciente del trabajo en salud produce efectos sobre la calidad de la asistencia. La especificidad del trabajo en salud y suas exigencias de trabajo psíquico se discuten examinando sus consecuencias para la calidad del cuidado. Algunas posibilidades de análisis y planteamiento de la dimensión inter-subjetiva/inconsciente del trabajo en salud se presentan y pueden contribuir para un nuevo modo de producir la gestión del cuidado en salud.

Palabras clave: Prestación de atención de salud. Subjetividad y gestión. Humanización de la atención.

Recebido em 17/11/08. Aprovado em 19/06/09. 